\title{
Correction to: The effect of fornix deep brain stimulation in brain diseases
}

\author{
Huajie Liu ${ }^{1,2} \cdot$ Yasin Temel $^{1,2} \cdot$ Jackson Boonstra ${ }^{1,2} \cdot$ Sarah Hescham ${ }^{1,2}$ (D)
}

Published online: 14 July 2020

(c) Springer Nature Switzerland AG 2020

\section{Correction to: Cellular and Molecular Life Sciences https://doi.org/10.1007/s00018-020-03456-4}

After publication of the original article it came to the authors' attention that there was an error under the subheading Traumatic Brain Injury (TBI) as well as Table 1. The study of Miller et al. [1] was conducted on drug-resistant epilepsy patients, not in TBI patients.

\section{Reference}

1. Miller J, Sweet J, Bailey C, Munyon C, Luders H, Fastenau P (2015) Visual-spatial memory may be enhanced with theta burst deep brain stimulation of the fornix: a preliminary investigation with four cases. Brain 138(7):1833-1842. https://doi.org/10.1093/ brain/awv095

Publisher's Note Springer Nature remains neutral with regard to jurisdictional claims in published maps and institutional affiliations.

The original article can be found online at https://doi.org/10.1007/ s00018-020-03456-4.

Sarah Hescham

sarah.hescham@maastrichtuniversity.nl

1 Department of Neurosurgery, Maastricht University Medical Center, PO Box 5800, 6202 AZ Maastricht, The Netherlands

2 European Graduate School of Neuroscience (EURON), Maastricht University, Maastricht, The Netherlands 